\title{
Commentary
}

\section{Diverticular disease and your mother's diet}

The concept that what our mothers ate while we were developing in utero, or even at our conception, might determine our disease risk in later life is both exciting and disturbing. It is a notion we have all accepted at a distance when reading about maternal folate intake and neural tube defects in the fetus, but there is more to this story.

Babies who are small for dates at birth have increased risk of cardiovascular disease and non-insulin dependent diabetes mellitus as adults. ${ }^{12}$ The theory that fetal nutrition influences adult disease risk has been established as the result of a series of observation studies and animal experiments by Professors Barker and Hales. ${ }^{1-3}$ The mechanism is thought to lie through metabolic adaptation in the fetus and placenta by changes in the secretion of hormones such as insulin and insulin-like growth factor, which lead to reduced intrauterine growth and subsequent insulin resistance in adult life. Nutrition here is not the sort that is associated with starvation, but is one end of the spectrum seen in the United Kingdom and other developed countries at birth weights of 3.2 to $4.2 \mathrm{~kg}{ }^{4}$

In characteristically discerning style, Martin Eastwood and colleagues have carried this theory over to the gut and shown, in an extended dietary study with rats, that maternal diet seems to affect the risk of colonic diverticular disease in their offspring. ${ }^{5}$ Three groups of 20 young rats were fed a high or low fibre diet, having been born to mothers fed the same diets from one month before mating. Fibre, measured as non-starch polysaccharides (NSP), was 1.7 and $13.3 \%$ of the diet. ${ }^{6}$ NSP in the human diet is in the range of $2-6 \%$. At the end of the study $42 \%$ of rats born to mothers fed a low fibre diet and fed low fibre themselves (FLF) had colonic diverticula, all in the mid and left colon. Those fed a high fibre diet and born to high fibre fed mothers (FHF) had $0 \%$ diverticula. More importantly $21 \%$ of those rats fed low fibre diets when the mother had had high fibre (WLF) had diverticula - a significant difference from the FHF and FLF groups. A useful further control would have been a group of rats fed a high fibre diet after being born to mothers fed low fibre.

In an attempt to understand the pathology of this condition, collagen cross linking was assessed in various regions of the colon from its solubility in weak acid. Acid solubility was lower (more cross linking) with the FLF (low fibre) than the FHF (high fibre) diet and in rats with diverticula than their litter mates without. Collagen content was similar at all sites and on all feeding regimens. Acid solubility of collagen in the WLF group did not show clear differences from the FLF group, so maternal diet did not seem to have a clear effect on collagen cross linking, although the high fibre group (FHF) showed significantly higher acid solubility throughout the transverse, descending, and sigmoid colon.

No study is perfect and this one produced some odd additional findings, particularly the distribution of testicular tumours among the groups and hepatic, pulmonary, and pancreatic abnormalities. All the animals were male and the diets varied in carbohydrate and protein contents as well as NSP, and were very low fat. ${ }^{6}$ One fascinating observation was the final weight of the animals, $912 \mathrm{~g} \mathrm{FLF}, 740 \mathrm{~g} \mathrm{WLF}$, and $590 \mathrm{~g} \mathrm{FHF}$. Details of food intake are not given in the paper but the energy content of the diets was not that dissimilar. Does a maternal high fibre diet prevent overweight in the offspring? An intriguing prospect of much more public health importance than diverticular disease.

Nevertheless, this study produced evidence of an effect of maternal diet on risk of developing colonic diverticula. What are the possible mechanisms? The role of fibre in protecting against diverticular disease has been known for more than 50 years since the animal studies reported by Carlson and Hoelzel ${ }^{7}$ who, in addition to concluding from their experiments 'that divericulosis of the colon in ageing rats is produced by the lack of a suitable kind and amount of roughage in the diet', noted that the most severe diverticulosis was found in the offspring of one particular female, whose diet had not been controlled during pregnancy, and suggested a genetic susceptibility. However, it was Painter and Burkitt in $1971^{8}$ who looked at the epidemiology of this condition worldwide and proposed the fibre deficiency hypothesis for its aetiology. Painter subsequently showed that symptomatic diverticular disease could be treated successfully with bran, ${ }^{9}$ a study that changed the practice of many gastroenterololgists. Over the subsequent 15 years there were a large number of further reports and studies, mostly confirming the general dietary fibre hypothesis.

The Barker and Hales studies ${ }^{1-3}$ leads us to look for a mechanism at the genetic or biochemical programming level. Which component of a maternal high fibre diet might moderate fetal gut development? We don't know which genes are involved in determining risk of diverticular disease although they could be related to those that affect aging. High fibre diets do moderate blood glucose and insulin responses, generally reducing them, and also produce short chain fatty acids through fermentation. Of the short chain fatty acids, butyrate is known to regulate gene expression in many cell lines. ${ }^{10}$ However present knowledge does not really allow a clear genetic, biochemical or developmental theory to be put together.

What is more certain about high fibre diets is that they are an important determinant of colonic bacterial growth and metabolism. ${ }^{11}$ So the female rats in the study by Wess et al who were fed the high fibre diet may well have had a different intestinal flora from those on low fibre. There is some evidence that we derive our gut flora in part from our mothers ${ }^{12}$ and this might be more so in rats living enclosed in a cage. Large bowel function is influenced considerably by diet through the activity of the resident flora, both in terms of motility, bowel habit, and epithelial cell function. Might the characteristic muscular hypertrophy seen in diverticular disease be due to bacterial metabolites derived from food residues? Thus present and 
maternal diet could be important contributors through effects on the flora.

After a decade of inertia in diverticular disease research this study presents us with some intriguing possibilities. It clearly needs to be extended to look at other maternal diets, to a closer examination of how we acquire our colonic flora, its metabolic potential in early infancy, and whether intestinal smooth muscle is affected by luminal amines and other possible neuro-active substances. We should also consider the importance of the Barker-Hales hypothesis for the gut. Now is the time to move on from the theory of low fibre and increased pressures in the sigmoid colon with which Painter and Burkitt challenged us all 25 years ago.

MRC Dunn Clinical Nutrition Centre,

JOHN H CUMMINGS Cambridge

1 Barker DJP, Gluckman PD, Godfrey KM, Harding JE, Owens JA, Robinson JS. Fetal nutrition and cardiovascular disease in adult life. Robinson JS. Fetal nutrition
Lancet 1993; 341: 938-41.
2 Hales CN, Barker DJP, Clark PMS, Fall C, Osmond C. Fetal and infant growth and impaired glucose tolerance at age 64. BMf 1991; 303: 1019-22.

3 Ozanne SE, Smith GD, Tikerpae J, Hales CN. Altered regulation of hepatic glucose output in the male offspring of protein-malnourished rat dams. Am 7 Physiol Endocrinol Metabol 1996; 33: E559-64.

4 Lithell HO, McKeigue PM, Berglund L, Mohsen R, Lithell U-B, Leon DA. Relation of size at birth to non-insulin dependent diabetes and insulin concentrations in men aged 50-60 years. BMF 1996; 312: 406-10.

5 Wess L, Eastwood MA, Busuttil A, Edwards C, Miller A. An association between maternal diet and colonic diverticulosis in an animal model. Gut 1996; 39: 423-7.

6 Wess L, Eastwood MA, Edwards CA, Bustuttil A, Miller A. Collagen alteration in an animal model of colonic diverticulosis. GUT 1996; 38:
allen A. Collagen alteration

7 Carlson AJ, Hoelzel F. Relation of diet to diverticulosis of the colon in rats. Gastroenterology 1949; 12: 108-15.

8 Painter NS, Burkitt DP. Diverticular disease of the colon: a deficiency disease of Western civilisation. BMf 1971; 2: 450-4.

9 Painter NS, Almeida AZ, Colebourne KW. Unprocessed bran in treatment of diverticular disease of the colon. BMF 1972; 2: 137-40.

10 Cummings JH, Short chain fatty acids. In: Gibson GR, Macfarlane GT, eds. Human colonic bacteria: role in nutrition, physiology and pathology. Florida: CRC Press 1995; 101-30.

11 Cummings JH, Macfarlane GT. The control and consequences of bacterial fermentation in the human colon. $\mathcal{A}$ Appl Bacteriol 1991; 70: 443-59.

12 Bond JH, Engel RR, Levitt MD. Factors influencing pulmonary methane excretion in man. An indirect method of studying the in situ metabolism of the methane-producing colonic bacteria. F Exp Med 1971; 133: of the $572-88$. 